VARIA 


\title{
A carta final de Carlos a Joaninha - justificações e outros lamentos
}

\author{
João Camilo dos Santos \\ University of California (EUA)
}

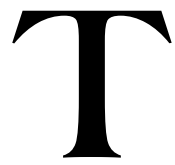

em-se falado muito na importância da novela da "menina dos rouxinóis" na estruturação de Viagens na minha terra, de Almeida Garrett. E com boas razões. Mas sem razão quando se destaca esse episódio para desvalorizar o resto. Obra híbrida, com aparência de narrativa de memórias, na realidade novela, ou romance, ou simplesmente narrativa, que se procura enquanto tal, deambulando entre a ficção e as histórias (a História colectiva e a história individual), Viagens na minha terra surge, mesmo antes de o romance moderno português se ter conseguido impor e atingir a maturidade (com Júlio Dinis, Camilo e Eça), como a obra que, aparentemente antes do tempo, se coloca a questão da própria possibilidade de se escreverem romances.

Com a sua sólida formação arcádica, Garrett conhecia demasiado bem as dificuldades e os artifícios do estilo para não desconfiar da literatura mesmo quando tentava afirmar-se como escritor. Essa lucidez e a sua conhecida sinceridade, uma notável capacidade de se distanciar, enquanto homem e enquanto escritor, do ambiente político e literário em que também ocupava um lugar visível, explicam certamente o interesse da sua obra para nós hoje ainda.

É nas Viagens que se encontram os primeiros exemplos portugueses de monólogo interior moderno, da corrente de consciência. ${ }^{1}$ Garrett é por outro lado sem ambiguidade o primeiro dos nossos escritores modernos, aquele que inicia um percurso que de algum modo só parece ter-se

\footnotetext{
${ }^{1}$ Assinalei a prioridade de Garrett e estudei esta questão em pormenor no meu artigo "Formas de 'corrente de consciência' em algumas narrativas do século XIX - os exemplos precursores de Alexandre Herculano e Almeida Garrett", Paris, Arquivos do Centro Cultural Português, Fondation Calouste Gulbenkian, Vol. XXXII, p. 195-234, 1993.
} 
concluído com Mário de Sá-Carneiro e Fernando Pessoa. As Viagens também permitem afirmá-lo e prová-lo e já vai sendo tempo de se estabelecer com clareza uma ponte mais visível entre estes dois momentos da modernidade na literatura portuguesa, entre Garrett, o ponto de partida, e Orpheu, meta de chegada (e o facto de Orpheu ser meta de chegada não impede que seja também ponto de partida, início de outra coisa). Lugar comum feliz tornou-se ligar as Viagens ao surgir de uma prosa portuguesa moderna, moldada na linguagem quotidiana, despretensiosa, oral, banal até, em vez de calcada nos modelos literários antigos ou simplesmente anteriores, sentidos sem dúvida pelo lúcido Garrett como artificiais, mentirosos, senão ridículos. Nada de surpreendente, pois a coerência de Garrett é ainda neste caso evidente: a compilação do Romanceiro e a insistência de Garrett na importância da "cultura popular", juntas com certo desprezo pela literatura e pela "cultura culta" dos literatos, estão de acordo com as escolhas estilísticas feitas nas Viagens. Já antes dos realistas, dos naturalistas e sobretudo dos neo-realistas, Garrett, de resto romântico genuíno nessa atitude, parece ter visto no povo e na cultura popular a possibilidade de nos salvarmos, que mais não fosse literariamente, como país. O falhanço da revolução e da ideologia liberal, que Garrett decretou e por várias vezes lamenta e condena, justifica certamente, em seu espírito, este deslocar da esperança. O início das Viagens, com a narração da disputa entre campinos e pescadores, é também ele claro no que respeita à importância que Garrett atribui agora ao povo miúdo, às massas populares. E no entanto Garrett tem sido visto algumas vezes por alguns, erradamente, apenas ou sobretudo como um modelo de dandismo aristocrático e artificial. Que Garrett tenha representado a sua parte na comédia que é a vida social, é possível e mesmo verdade; mas a sua obra revela a todos os níveis, para além do dandismo e do gosto pelo artifício, a figura de um intelectual lúcido, de um pensador que não receou pôr em causa os valores aceites pela sociedade da sua época, de um escritor em cuja obra repetidamente se anunciam preocupações futuras. Garrett pressentiu a modernidade com uma lucidez que pode surpreender.

Mas então, e a carta de Carlos a Joaninha? Essa carta é de facto um monumento importante, provavelmente o primeiro manifesto, simultaneamente político, social, moral e literário, da nossa modernidade. Vemola elevar-se acima da mediania de outros discursos como um marco a dividir as águas, isto é, a separar o passado do futuro. Cartas têm-se escrito muitas. E das perigosas cartas libertinas do romance político de 
Laclos à paixão das cartas atribuídas à freira portuguesa os exemplos ilustres e susceptíveis de provocar sábias reflexões de interesse para várias disciplinas não faltarão. Aconteceu-me também pensar, ao reler agora a carta de Carlos a Joaninha, em Saul Bellow e nesse extraordinário romance moderno que é Herzog (1964). A partir daí pensei na carta de Kafka ao pai. As cartas são efectivamente com frequência a expressão de uma torturada vontade de diálogo e simultaneamente uma excelente maneira de tentarmos justificar-nos. E através delas vamos escrevendo a nossa história. Se lhes damos e temos dado tanta importância é certamente porque o que nelas e na obsessão que frequentemente revelam se joga sempre é o sentido da existência de quem as escreve - e fatalmente também de quem as lê.

A carta de Carlos a Joaninha tem a antecedê-la e a segui-la ilustres monumentos literários. Mas se os cinco capítulos por que se estende esta carta lhe conferem um lugar importante na história da nossa literatura, dos nossos costumes, da nossa mentalidade, é porque na sua aparente ligeireza e insignificância o que repetidamente se manifesta é a torturada e engenhosa tomada de consciência das nossas bem modernas contradições. Essa carta é importante porque nela se descobre e denuncia a complexidade pouco lógica dos afectos, dos desejos, das vaidades, isto é, daquilo a que chamamos amor; e é importante também porque nela, na sua estratégia tortuosa, nessa impossibilidade de destrinçar o que é sincero do que pode ser simplesmente talento verbal de sedutor barato, se anuncia já também a problemática do fingimento e da sinceridade, da verdade e da ficção, que para Fernando Pessoa será uma preocupação constante e fundamental. Justifica-se plenamente, portanto, que consideremos Garrett um lúcido precursor de Júlio Dinis, Camilo, Eça, Cesário Verde e outros, por um lado, do modernismo português do Orpheu por outro.

Não será atribuir excessiva importância a uma simples carta de amor? Resta saber se se trata de uma carta de amor. Antes parece tratarse de uma "carta de amores". E logo aí se iniciam os malentendidos e as contradições. É a Joaninha que Carlos escreve e aparentemente escrevelhe porque a amou e a ama. Mas se repararmos bem, as palavras de amor de Carlos para Joaninha são apenas uma espécie de leitmotiv que ao longo da carta se vai repetindo, de maneira relativamente monótona porque um tanto idêntica, sem muita imaginação. Na realidade o que acontece é que Carlos, repetindo a Joaninha que a ama, a obriga a ser sua confidente - visivelmente para lhe poder falar em seguida longamente 
sobretudo das outras mulheres que amou. Quem, melhor do que aqueles que nos amam ou pensam que são amados por nós, nos poderia escutar com tão sincero interesse?

O talento de dramaturgo de Garrett transparece na utilização que ele faz da carta para transmitir ao leitor, e não só a Joaninha, sobre Carlos, uma série de informações que considera pertinentes e interessantes. É provável que este detalhe de ordem retórica tenha interferido com a impressão final que nos deixa a carta e condicione portanto os comentários que sobre ela e sobre Carlos se podem fazer; mas temos de haver-nos com o que Garrett nos deu e ele tem de aceitar as consequências das escolhas narrativas que fez.

Surpreende, de facto, o prazer e o entusiasmo que Carlos manifesta em voltar sobre a história antiga dos seus curiosos amores com as raparigas inglesas. Surpreende ainda mais que esse entusiasmo e esse prazer se manifestem numa carta dirigida a Joaninha porque é nessa mesma carta que ele diz, sem recear as contradições e sem recear feri-la, que a ama, que sempre a amou. Mais contradições e ainda susceptíveis de ferir Joaninha e de negar todo o amor que ele pretende ter-lhe tido e ter ainda: é contando-lhe a ela a história das suas relações com as raparigas inglesas que ele afirma por várias vezes ter conhecido sentimentos que nunca conhecera antes, momentos de felicidade indescritíveis e raros. E Joaninha, então? O amor tão extraordinário que ele diz sentir por Joaninha, a prima querida da infância cuja imagem, diz ele, por todo o lado o acompanhou, não lhe permitiu conhecer nada que se mencione e recorde, nenhum sentimento excepcional que merecesse ser citado como único? Carlos nem se dá ao trabalho retórico de inventar, Joaninha não lhe merece sequer o esforço e os minutos de uma mentira piedosa. E o leitor que se dá conta disso pergunta-se: mas afinal, o que é que Carlos pretende de facto com esta carta?

É evidente que o prazer de recordar amores antigos é na carta mais importante do que a declaração de amor a Joaninha que a mesma carta poderia ser e pretende, curiosamente, ser. Carlos imagina, porém, que pode escapar à contradição - e à argúcia de Joaninha e do leitor. Ela morrerá louca, sabemo-lo mais tarde, e não sabemos senão isso. Devemos dizer que se Joaninha o amava - acreditamos que sim - o comportamento contraditório dele lhe deu suficientes razões para enlouquecer e morrer. Mas é tentando escapar às suas contradições que Carlos desenvolve na carta uma curiosa estratégia de defesa. Diz ele, depois de dizer a Joaninha 
que a ama, que não a pode amar. Porquê? Porque é um monstro, vítima do seu temperamento e energia, e não é capaz de amar ninguém. Não tem culpa. Até sofre com isso, diz ele. Mas é assim, e mulher que casasse com ele seria forçosamente infeliz. Não sou digno de ti, Joaninha, confessalhe. A gente franze o sobrolho e pensa: estaremos já aqui perante uma das numerosas personagens de Eça que nunca se casam, que só têm relações passageiras com as mulheres, dormindo com elas para depois as evitar? Será o Carlos desta carta parente das personagens do romance de Laclos? Será esta carta a prova de que Carlos é um indivíduo sem escrúpulos, já com as "qualidades" (e lá volta Eça a acenar-nos) do primo Basílio? Dândi sem escrúpulos que abusa da inocência da prima e do amor profundo e ingénuo que ela lhe tem, Carlos poderia pelo menos evitar ter ido tão longe na hipocrisia. A vaidade de conquistador de que dá provas também não contribui para nos dar de Carlos uma imagem muito positiva. Para quê escrever a Joaninha a dizer-lhe que a ama numa carta onde diz que é um monstro que não pode amá-la? E sabendo que ela o ama, porque a tortura, porque confunde ele o frágil espírito da prima relatando-lhe as suas aventuras amorosas do exílio em Inglaterra?

$\mathrm{Na}$ realidade Joaninha não é nunca a personagem principal desta carta, visto que não passa de um pretexto de que Carlos se serve para confessar (ou tornar públicas?) as suas descobertas sobre si mesmo. Carlos faz da prima, usando do pretexto de a ter amado, a confidente e a testemunha de que necessita para contar as suas aventuras amorosas. Usa-a também para debater (consigo mesmo, além disso, e não só com ela) problemas nascidos do seu comportamento ou provocados pelos seus sentimentos (e ele não pode fugir a um nem aos outros). Obrigado a fazer face a uma imagem de si próprio que ele pretende estranhar, Carlos fala à prima (e ao leitor, ao futuro) da sua perplexidade.

Uma das novidades e interesse deste livro e desta carta reside precisamente nas questões que acabo de levantar. Deixemos de lado a possível imperfeição técnica: pode ter sido um erro de Garrett ter querido transmitir tantas informações simultaneamente ao leitor e a Joaninha pela boca - pela pena - de Carlos numa única carta. De qualquer modo ele sente-se culpado, não tanto, provavelmente, porque se acusa a si próprio de monstro, como devido à estratégia ambígua que adopta para desiludir Joaninha numa carta em que se despede para sempre dela.

Surge aqui, parece que pela primeira vez na literatura moderna, um conflito e um drama que vai caracterizar a literatura da época de 
Baudelaire e Cesário Verde, e que reside na atracção conflituosa pelos múltiplos amores, pela vagabundagem afectiva e sexual, por um lado, e por uma vida doméstica num lar protegido, por outro. Recorde-se "O Sentimento de um Ocidental" de Cesário, por exemplo, e a alusão nostálgica aos "querubins do lar" que "flutuam nas varandas" e às mansões de vidro transparentes. Nos Cus de Judas (1979), de Lobo Antunes, encontramos repetidamente a mesma atracção pelo amor doméstico e protegido do lar: o sedutor, narrador e protagonista do romance, enquanto passeia por Lisboa o seu dandismo e a sua solidão, exprime com clareza a sua frustração com os amores passageiros e com as aventuras sexuais em que não encontra o prazer nem a plenitude que procura. Não custa entender que o Carlos de Garrett seja de facto incapaz de resolver um conflito que pelos vistos caracteriza a época moderna e que tem torturado tantos espíritos.

É por isso também que esta carta e este livro me parecem importantes. A confissão meio-sincera, meio-leviana, meio-dândi de Carlos, na medida em que se opõe aos princípios morais e sociais em vigor na época, revela certa coragem no pensar e no falar. É como se o mais importante para Carlos fosse de facto tentar entender esta contradição, que sem dúvida o surpreende, e para a qual a única explicação que encontra é a de se considerar, para se desculpar até certo ponto pelas suas contradições, "um monstro". E então, por narcisismo doentio, Carlos esquece-se de que o que diz a Joaninha a pode destruir. Ou quer magoá-la para, agindo monstruosamente, definitivamente se libertar do peso do amor dela? As contradições da cabeça e do coração, o conflito entre o que aprendeu que era o amor e o que ele descobriu que o amor é deixaram-no confuso, talvez meio tolo e torturado. Talvez, também, a excitação com a descoberta das suas contradições o deixe entusiasmado consigo mesmo e com a vida. Talvez não fosse Joaninha, porém, a mulher mais indicada para ouvir uma confissão de tantas consequências, em que se inicia uma época nova das relações amorosas entre os sexos. Mas Carlos, estouvado, não encontrou outra mulher a quem confessar a sua perplexidade, a quem anunciar um futuro carregado de consequências. E de resto, quem melhor do que aqueles que podemos magoar prestará atenção às nossas confidências?

Na sua "carta-testamento" Carlos diz afinal: 
desculpa, Joaninha, eu amo-te, mas não posso amar-te, aliás já amei várias mulheres, estranhamente, confusamente, amei-as ao mesmo tempo ou quase ao mesmo tempo, e descobri coisas curiosas (ficar contente com a partida da mulher que amava, por exemplo; surpreende-me que possa ter sentido isso). Nada a fazer, não entendo nada de mim nem do amor.

A parte final da carta, porém, é mais clara ainda a este respeito:

Eu, sim, tinha nascido para gozar as doçuras da paz e da felicidade doméstica; fui criado, estou certo, para a glória tranquila, para as delícias modestas de um bom pai de família.

Mas não o quis a minha estrela. Embriagou-se de poesia a minha imaginação e perdeu-se; não me recobro mais. A mulher que me amar há-de ser infeliz por força, a que me entregar o seu destino há-de vêlo perdido.

Não quero, não posso, não devo amar a ninguém mais.

A desolação e o opróbrio entraram no seio da nossa família. Eu renuncio para sempre ao lar doméstico, a tudo quanto posso querer. Deus que me castigue, se ousa fazer uma injustiça, porque eu não me fiz o que sou, não me talhei a minha sorte, e a fatalidade que me persegue não é obra minha. ${ }^{2}$

Alusões a uma situação familiar - o pecado original dos pais - em que Carlos parece descobrir não se sabe se a fatalidade naturalista da hereditariedade, se simplesmente um mau exemplo. Ainda neste ponto há conhecidas semelhanças entre este Carlos das Viagens e o Carlos de Os Maias de Eça de Queirós; é como se ambos fossem vítimas de uma situação familiar que os condiciona e que os torna menos responsáveis pelas suas contradições e atitudes perante o amor e as mulheres. Este excerto explica com bastante clareza a situação tal como Carlos a vê.

Que há nesta carta muitas elipses não é difícil imaginá-lo. Carlos não pode confessar com mais clareza que prefere, ${ }^{3}$ como o outro Carlos

${ }^{2}$ GARRET, 1960, p. 243.

${ }^{3}$ Evidentemente, há sempre a possibilidade de nos interrogarmos honestamente sobre uma outra questão, intimamente relacionada com estas: as personagens de Garrett e de Eça, e além disso as da História contemporânea, escolhem de facto o seu destino ou são vítimas de uma inexplicável impossibilidade de amar? Mas a essa pergunta não terei a pretensão de querer responder. 
mais tarde, o de Os Maias de Eça, as aventuras amorosas sem compromisso ao casamento, ao amor único. Carlos da Maia vai para Paris, onde lhe parece que pode levar a vida de prazeres de um dândi que tem dinheiro para os comprar. O Carlos de Garrett faz-se barão, engorda, e também enriquece. Serão precisas mais provas de que Garrett é o precursor lúcido de toda uma geração romântico-realista na literatura portuguesa?

O futuro das relações entre os dois sexos, uma nova moral amorosa - a "desordem amorosa moderna", título de um livro de Alain Finkielkraut, autor francês contemporâneo - estão já anunciados com suficiente clareza nas Viagens de Garrett, obra que torna de antemão mais compreensível o que Júlio Dinis, Camilo, Eça e Cesário Verde não deixarão de pôr suficientemente em evidência. Acabou-se, então, o tempo de Petrarca e do sublime e mais puro sofrimento amoroso? Camões já mostrara grande sensiblidade às contradições do coração e o esboço da revolta e desta nova ordem já se poderão descortinar nos seus sonetos e canções da maturidade. Agora, porém, já não é o "desconcerto do mundo" que se assinala, mas o "desconcerto" ou "perdição" do indivíduo, que além do mais se crê em parte responsável pelas suas contradições e volubilidade "monstruosa", apesar de ao mesmo tempo se afirmar vítima de uma misteriosa fatalidade. Esta nova lei do amor serão Eça e Machado de Assis, muito melhor do que Flaubert, a enunciá-la e a ilustrá-la quando põem em cena os Brás Cubas, os Carlos da Maia, as Luísas e os primos Basílios. O flirt, ambíguo e que deveria proteger da tragédia do amorpaixão, é referido nas Viagens como uma excitante descoberta de Carlos em Inglaterra. Essa maneira de se relacionarem os homens e as mulheres parece ter progressivamente emigrado depois da ilha britânica para o resto da Europa e para outros continentes. O Carlos das Viagens é por isso, e por tudo o que isso implica, claramente um ilustre precursor das personagens de Eça e Machado de Assis e das intrigas amorosas em que estas se vêem envolvidas, que fazem das suas existências ora uma modesta e íntima tragédia, ora uma felicidade discreta e sem alaridos.

Repare-se ainda, para terminar, que consciente da dificuldade que consistia em apresentar aos seus contemporâneos uma nova moral das relações amorosas, Garrett recorre por duas vezes ao mesmo processo: acusa num caso Carlos de "poeta", para justificar os devaneios que nos dá em directo da corrente da sua consciência; e fá-lo acusar-se em seguida de "monstruoso", para que fique claro que ele próprio, Carlos, tem consciência de que está a infringir uma lei e a negar o conhecimento que 
o senso comum pretende ter do ser humano. A desculpa da anormalidade permitiu a Garrett, que pressentira a verdade (ou a dificuldade de alcançar a verdade) sobre o coração e o desejo humanos, anunciar o futuro. A evolução que entretanto se verificou nos costumes torna desnecessário hoje o recurso a esta estratégia. A "anormalidade" é hoje aceite como uma das nossas formas de ser normais. Mas, ainda no século XIX, já as personagens de Alves e companhia de Eça se debatiam com problemas domésticos tão mesquinhos e acabavam por resolver com tanta naturalidade e descaramento a questão da dessacralização do amor e a questão do adultério, que depois disso parece não se ter inventado nem descoberto mais nada. Em Garrett parece que estava já tudo. Ou quase tudo, enfim.

\section{Referências}

GARRET, Almeida. Viagens na minha terra. $4^{a}$ edição. Porto: Livraria Figueirinhas, 1960.

\section{Resumo}

Análise crítica do papel da novela da "menina dos rouxinóis" na estruturação do romance Viagens na minha terra, de Almeida Garrett.

\section{Résumé}

Il s'agit d'une analyse critique du rôle du récit "menina dos rouxinóis" dans la structuration du roman Viagens na minha terra de Almeida Garrett. 